\title{
DIREITOS DA PESSOA COM DEFICIÊNCIA E SEUS AVANÇOS JURÍDICOS E SOCIAIS
}

\author{
RIGHTS OF THE DISABLED PERSON AND THEIR LEGAL AND SOCIAL \\ ADVANCES
}

\author{
Maurício Ferreira da Cruz Junior ${ }^{1}$ \\ Joelma Coimbra dos Santos ${ }^{2}$ \\ Romulo Renato Cruz Santana ${ }^{3}$
}

\begin{abstract}
Resumo: O presente trabalho tem como objetivo apresentar um estudo sobre os direitos da pessoa com deficiência e seus avanços jurídicos e sociais, sob uma aparente evolução dos direitos humanos na perspectiva da pessoa com deficiência. A indagação norteadora do texto parte de como são desenvolvidas as bases protetivas jurídicas e sociais em favor das pessoas com deficiência no Brasil. Para isso, mostra-se como objetivo geral, analisar o contexto da evolução dos direitos humanos e se tal evolução abrange ou dá subsídios para a delimitação da normatividade da inclusão para a pessoa com deficiência. Como objetivos específicos, faz-se necessário esmiuçar o conceito de pessoa com deficiência dentro dos direitos humanos e sua finalidade, assim como estudar os princípios correlatos, bem como evidenciar quais as necessidades de serem aplicadas adequadamente. Ainda como objetivos específicos, precisa-se mostrar também o quão são importantes os movimentos para que haja uma conquista de garantias, demonstrando quais foram os procedimentos tomados para que as evoluções obtivessem sucesso e alcançaram o devido reconhecimento pelas autoridades e toda a sociedade, com base também nas alterações promovidas pela Lei $13.146 / 2015$, que intitula o Estatuto da Pessoa com Deficiência que é a lei que tem uma grande relevância para todos com algum tipo de deficiência. A pesquisa, ora desenvolvida, baseou-se no método hipotético dedutivo, na revisão documental e bibliográfica, a exemplo das normativas expostas ao longo do texto em breves linhas, apoiada em referenciais como Ihering (1979), Lanna Júnior (2010), Piovesan (2018), Madruga (2016), dentre outros não menos
\end{abstract}

\footnotetext{
${ }^{1}$ Doutorando em Direito Político e Econômico pela Universidade Presbiteriana Mackenzie. Mestre em Direito, com sub-área em Direitos Humanos pela Universidade Federal de Mato Grosso do Sul-FADIR. Professor da Famp - Faculdade Morgana Potrich. Coordenador da Comissão Própria de Avaliação FAMP. Líder do Grupo de Estudo "Núcleo de Estudos Jurídicos" NEJ-FAMP. Foi Bolsista de Pós-Graduação CAPES. Membro do grupo de pesquisa "Laboratório de Estudos e Pesquisa em Direitos Difusos-LEDD) da Universidade Federal de Mato Grosso do Sul-FADIR. Graduado em Direito pela Universidade Federal de Mato Grosso do Sul-CPTL. . Tem experiência na área de Direito, com ênfase em Direitos Humanos e minorias, atuando principalmente nos seguintes temas: Direitos Fundamentais, Direitos Humanos, Direito Educacional, Pessoas Idosas, Políticas Públicas e Qualidade de vida.

2 Possui graduação em Pedagogia pela UNIVERSIDADE ESTADUAL DO TOCANTINS(2011). Atualmente é Diretora da Associação Pestalozzi de Alto Taquari. Tem experiência na área de Educação, com ênfase em Dirigente.

${ }^{3}$ Mestre em Educação pela Universidade Federal de Goiás - Regional Jataí. Especialista em Gestão de Sala de Aula no Ensino Superior, pelo Centro Universitário de Mineiros- UNIFIMES. Especialista em Direito Tributário pela Universidade Anhanguera - UNIDERP - Rede LFG. Graduado em direito pela Faculdade de Tecnologia e Ciências de Salvador (2006).
} 
relevantes. Por meio dessa produção, foi possível ainda refletir que é necessário oportunizar subsídios para a iniciativa pública e privada assegurar não só os direitos humanos como também uma sociedade pautada na acessibilidade da pessoa com deficiência, sob todos os aspectos preconizados na Lei $n^{0} 13.146$, e o passo importante pode ser dado através da difusão do conhecimento, bem como de qualquer experiência exitosa alcançada onde a pessoa com deficiência é a beneficiada.

Palavras-chave: Pessoa com Deficiência. Importância dos Primeiros Movimentos em favor da pessoa com deficiência. Lei no 13.146/2015.

Abstract: This paper aims to present a study on the rights of people with disabilities and their legal and social advances, under an apparent evolution of human rights from the perspective of people with disabilities. The text's guiding question is how the legal and social protective bases are developed in favor of people with disabilities in Brazil. For this, the general objective is to analyze the context of the evolution of human rights and whether such evolution covers or supports the delimitation of the normativity of inclusion for people with disabilities. As a specific objective, it is necessary to scrutinize the concept of people with disabilities within human rights and its purpose, as well as to study the related principles, as well as highlighting the needs to be properly applied. Still as specific objectives, it is also necessary to show how important the movements are for the achievement of guarantees, demonstrating what were the procedures taken so that the evolutions were successful and achieved due recognition by the authorities and the whole society, based on also in the changes promoted by Law 13,146/2015, which entitles the Statute of Persons with Disabilities, which is the law that has great relevance for everyone with some type of disability. The research, now developed, was based on the hypothetical deductive method, on document and bibliographic review, such as the regulations set out in brief lines throughout the text, supported by references such as Ihering (1979), Lanna Júnior (2010), Piovesan (2018), Madruga (2016), among others no less relevant. Through this production, it was also possible to reflect that it is necessary to provide subsidies for the public and private initiative to ensure not only human rights but also a society based on the accessibility of people with disabilities, in all aspects recommended in Law No. 13,146, and the An important step can be taken through the dissemination of knowledge, as well as any successful experience achieved where the person with a disability is the beneficiary.

Keywords: Person with Disabilities. Importance of First Movements in favor of people with disabilities. Law 13.146/2015.

Recebido em: $16 / 07 / 2021$

Aceito para publicação em: 25/10/2021 


\section{INTRODUÇÃO}

No que tange às pessoas com deficiência, os primeiros movimentos relacionados ao atendimento deste grupo, datam a partir do século XIX, no continente Europeu. França, Alemanha e Inglaterra iniciaram este movimento por meio de ações relacionadas à assistência na área da saúde. $\mathrm{O}$ atendimento acontecia em hospitais psiquiátricos ou como eram denominados na época, hospícios. Mais tarde esses, difundiram-se para outros países (MADRUGA, 2019).

No Brasil, começou-se a pautar as necessidades da pessoa com deficiência somente após a década de 70. Estas ações contaram com o apoio de representantes das diversas esferas públicas, bem como, das pessoas com deficiência, que apoiaram o movimento na busca por melhor qualidade de vida, ansiando terem os seus direitos resguardados de acordo com suas necessidades e amparados no âmbito legal (LANNA JÚNIOR, 2010).

Com o advento da Constituição da República Federativa do Brasil de 1988 , ficou estabelecida uma base consolidada de direitos fundamentais, possibilitando que debates específicos direcionados às pessoas com deficiência viessem a acontecer futuramente, como no caso da obrigatoriedade de acessibilidade, que tem por premissa, favorecer a locomoção desses indivíduos (BRASIL, 1988).

Oriunda de desdobramentos internacionais, em 2015 entrou em vigor a Lei 13.146, que intitula o Estatuto da Pessoa com Deficiência no Brasil, na qual, destacam-se uma gama de direitos fundamentais, além de prever garantias às pessoas com deficiência, também estabeleceu a responsabilidade do Poder Público em assegurar uma vida digna ao grupo em questão (BRASIL, 2015).

Desta forma, o presente trabalho visa analisar por meio de pesquisa, o seguinte problema: como são desenvolvidas as bases protetivas jurídicas e sociais em favor das pessoas com deficiência no Brasil? Consoante, foram analisados os caminhos dos direitos da pessoa com deficiência desde a Declaração Universal dos Direitos Humanos de 1948, pela qual se identificou em virtude do âmbito internacional, a necessidade de previsões legais na esfera nacional, criando-se assim, o Estatuto da Pessoa com Deficiência no Brasil. 
Para desenvolver a pesquisa e buscar respostas para a problemática acima mencionada, alguns objetivos foram elaborados. O objetivo geral teve como meta apresentar o caminho do desenvolvimento das bases protetivas, direcionadas às pessoas com deficiência no Brasil, e como objetivo específicos, faz-se necessário esmiuçar o conceito de pessoa com deficiência dentro dos direitos humanos e sua finalidade, assim como estudar os princípios correlatos, bem como evidenciar quais as necessidades de serem aplicadas adequadamente.

Ainda como objetivos específicos, precisa-se mostrar também o quão são importantes os movimentos para que haja uma conquista de garantias, demonstrando quais foram os procedimentos tomados para que as evoluções obtivessem sucesso e alcançaram o devido reconhecimento pelas autoridades e toda a sociedade, com base também nas alterações promovidas pela Lei 13.146/2015, que intitula o Estatuto da Pessoa com Deficiência que é a lei que tem uma grande relevância para todos com algum tipo de deficiência (BRASIL, 2015).

No tocante à metodologia, a pesquisa foi desenvolvida por meio de uma análise qualitativa, utilizando fontes indiretas, dentre elas: bibliográficas e documentais (LAKATOS; MARCONI, 2017, p. 69). Optou-se pela qualitativa, pois buscou desenvolver um raciocínio para apresentar o desenvolvimento dos direitos das pessoas com deficiência no Brasil. Consequentemente desenvolveu-se o método científico dedutivo, que por sua vez, mediante estudo e análise aprimorou a coleta de dados referentes ao tema: Pessoa com Deficiência e seus avanços conquistados (MEZZAROBA; MONTEIRO, 2019).

Sobre as fontes indiretas bibliográficas e documentais, foram utilizadas as bases Minha Biblioteca, Bases de teses e dissertações da CAPES Scielo, que ajudaram a desenvolver esta pesquisa, no tocante ao tema proposto por este trabalho.

Desta forma, verificou-se, quantitativamente (MEZZAROBA; MONTEIRO, 2019) que a popularização do termo Pessoas com Deficiência, tal como, a evolução constante dos recursos voltados às suas garantias, podem ser consideradas como grandes avanços para melhoria na qualidade de vida deste público.

Na Carta de São José da Costa Rica trás que o verdadeiro intuito da evolução dos direitos das Pessoas com Deficiência é assegurar que, os mesmos não sejam Revista Auditorium, Rio de Janeiro, v. 25, n. 52, p. 62-80, jul./out. 2021 
violados, nem omitidos pelas autoridades, assim como, pela sociedade em geral. Desse modo, verifica-se a importância de além de normatizar os direitos para as pessoas com deficiência no Brasil, mostra-se crucial sua efetividade, que resvalará no conhecimento social, a fim de que haja uma espiral propositiva acerca da condição legal, social e humana desses indivíduos

É de grande valia ressaltar que, dentro do direito há uma face oculta do estatuto constitucional quando se trata de indivíduos em geral, portanto, também está relacionado aos direitos da Pessoa com Deficiência. Segundo Nabais (2002), esta situação pode ser comparada a face oculta da lua, que é aquela parte que não é possível de ser vista, sendo necessário que este direito seja inserido no devido lugar onde o indivíduo está e, por conseguinte, o beneficiando em sede dos direitos fundamentais ou direitos humanos.

É de suma importância jogar luz sobre o tema por intermédio de: conferências, seminários, congressos, encontros, etc. Referente aos direitos fundamentais, deve ser tratado também o lado oculto, que por vezes, o mesmo passa despercebido pela sociedade e autoridades responsáveis.

Conclui-se por ora, que o Estado e naturalmente a soberania do povo que suporta a sua organização política, tendo por base a dignidade da pessoa humana, tem o direito de reivindicar os direitos de acordo com a necessidade e realidade atual.

\section{CONCEITO E OS PRIMEIROS MOVIMENTOS}

O início da caminhada em favor da pessoa com deficiência, teve como premissa possibilitar melhor qualidade de vida às pessoas com restrição física, mental ou sensorial, de natureza permanente ou transitória, que na sua maioria, afetam esses indivíduos nas capacidades de exercerem uma ou mais atividades essenciais da vida diária, assim deu-se a largada na pavimentação do caminhar do tema, pessoa com deficiência.

Ao referir-se sobre os primeiros movimentos, segundo Madruga (2016), pode ser considerado como um momento especial da luta em favor da pessoa com 
deficiência, a convenção sobre os Direitos das Pessoas com Deficiência, assinada em Nova York em 30 de março de 2007. Esta que respalda a evolução que vem ocorrendo no campo do Direito a partir da década de 1980, por corroborar com um modelo social e moderno que eleva a uma nova conceituação de deficiência:

\begin{abstract}
Pessoas com deficiência são aquelas que têm impedimentos de longo prazo de natureza física, mental, intelectual ou sensorial, os quais, em interação com diversas barreiras, podem obstruir sua participação plena e efetiva na sociedade em igualdades de condições com as demais pessoas (MADRUGA, 2016, p. 121).
\end{abstract}

Para Piovesan (2018), os Direitos Humanos foram criados e têm como objetivo defender e executar os direitos direcionados a toda e qualquer pessoa. É importante destacar que o direito é a proteção daqueles que são resguardados de acordo com suas necessidades. Vale ressaltar que os Direitos Humanos vêm obtendo avanços fundamentais em favor de toda sociedade ao longo da história, isso advém do maior interesse social e suas respectivas mobilizações. Leis, decretos, e outros meios legais para defesa da pessoa com deficiência, são exemplos desses avanços inseridos na sociedade.

Para Lanna Júnior (2010), os Movimentos das Pessoas com Deficiência passaram por grandes avanços nos últimos tempos. Nele, a interação entre a deficiência e o modo como a sociedade está organizada é que condiciona a funcionalidade, as dificuldades, as limitações e a exclusão das pessoas. Sobre tal, a sociedade quando desconhecedora cria barreiras, sejam elas com relação a atitudes por medo, desconhecimento, falta de expectativas, estigma e preconceito. No ambiente físico com barreiras arquitetônicas, bem como, as institucionais que se pautam em discriminações de caráter legal, todas essas impedem a plena participação das pessoas com deficiência. O principal fundamento, em termos paradigmáticos e estratégicos, é registrar que foi deslocada a luta pelos direitos das pessoas com deficiência do campo da assistência social para o campo dos Direitos Humanos, esse foi o maior objetivo conquistado, que visa derrubar as barreiras "atitudinais", arquitetônicas e institucionais.

Segundo Piovesan (2018), as organizações internacionais estimam que haja no mundo aproximadamente 650 milhões de pessoas com deficiência, número que 
corresponde a $10 \%$ da população mundial. Isso mostra o quanto é importante os movimentos em favor dessas pessoas, e como as normas e leis podem ser favoráveis para a melhoria na qualidade de vida das pessoas com deficiência, quando aplicadas devidamente.

A Carta de São José da Costa Rica (OEA, 1969) veio a ratificar, que os direitos considerados essenciais para a pessoa humana, não derivam do fato de onde ela é, mas sim de ser humano, esta é a verdadeira razão para justificar a devida proteção. É perceptível que todos os princípios foram consagrados na Carta da Organização dos Estados Americanos, na Declaração Americana dos Direitos e Deveres do Homem e na Declaração Universal dos Direitos do Homem, estes documentos respaldam ações no âmbito mundial, bem como nacional.

No tocante ao Brasil, houve um aumento na demanda com os crescentes conflitos armados. A Guerra dos Farrapos (Rio Grande do Sul 1835-1845), Canudos (Bahia 1896-1897). A participação do país na Segunda Guerra Mundial segundo Madruga (2019), contribuiu com os chamados "feridos de guerra", assim surgiram os serviços de assistência sociais institucionais, a educação especial, os benefícios de reabilitação médica e as cotas laborais.

As primeiras garantias só foram conquistadas tempos depois, em um processo lento pelo fato de que nem todos sentiam a importância de defender a pessoa com deficiência naquele momento. Em 1956, quando o Brasil estava passando por alguns outros acontecimentos históricos, destaca-se a construção da cidade de Brasília em 41 meses. Naquele momento, foram enviados vários ofícios e diversos contatos foram feitos às autoridades competentes, representantes governamentais e até mesmo contatos diretos com governadores. Os defensores das pessoas com deficiência vislumbravam com uma vida digna para essa parcela da sociedade, que padecia na vulnerabilidade naquele tempo (LANNA JÚNIOR, 2010).

Com a Constituição Federal de 1988, que tem por premissa estabelecer o Estado Democrático de Direito, nesta que foi intitulada de "constituição cidadã", a qual garantiu que os frutos de pesquisas adquiridas com a participação da sociedade brasileira, fossem levados em conta, com isso os debates acerca da igualdade surgiram, levando consigo as lutas da pessoa com deficiência, que tiveram sua voz ecoada no referido documento. Esse sentimento igualitário pode ser traduzido em Revista Auditorium, Rio de Janeiro, v. 25, n. 52, p. 62-80, jul./out. 2021 
diversos âmbitos, por meio de regras que o garantem, estando presente no art. $5^{\circ}$ da Constituição. Com o mesmo já seria o bastante para garantir a igualdade formal, ou seja, a igualdade perante a lei (ROTHENBURG, 2003).

Desta forma, os movimentos constitucionalistas brasileiros, tiveram papel fundamental no desenvolvimento das bases protetivas para as pessoas com deficiência, direta ou indiretamente, principalmente após Constituição da República Federativa do Brasil, ao ratificar a importância da sociedade humanista, democrática e cidadã (DALLARI, 2013).

Graças a todos os movimentos, interesses das autoridades competentes e dos autodefensores das garantias, que os direitos conquistados, assim como os direitos fundamentais criados pela necessidade de amparar as pessoas, garantem um direito justo. A sua evolução também se dá com a precisão de avanços até mesmo tecnológicos ofertados pelo tempo (ARAÚJO; JÚNIOR, 2006).

No que se refere ao âmbito geral, Cunha (2014) entende que qualquer lugar deve ser apropriado para uma pessoa com deficiência, ou seja, desde espaços físicos até as garantias pessoais como auxílios financeiros, entre outros. Tais conquistas só foram garantidas através de vários movimentos como já destacados, um bom exemplo são as conferências, em que os indivíduos com deficiência são incluídos como membros e solicitantes de seus direitos, fazendo com que os mesmos se tornem leis.

Para Facion (2005), no campo educacional, os direitos garantidos foram conquistados em grande parte, pela parcela da sociedade ligada diretamente a pessoas com deficiência, impulsionados pela conscientização social. Esta conquista foi adquirida de forma vagarosa, mas originou uma lei denominada: Lei da Inclusão Social, que garante ao público em questão com até 18 anos, o ingresso no ensino regular, considerando que a inclusão é uma via de mão dupla, tão logo, os demais estudantes do ensino regular se beneficiam desta convivência. Para Maurício Godinho Delgado (2007, p. 49):

Definir um fenômeno consiste na atividade intelectual de apreender e desvelar seus elementos componentes e o nexo lógico que os mantém integrados. Definição é, pois, a declaração da estrutura 
essencial de determinado fenômeno, com seus integrantes e o vínculo que os preserva unidos. (DELGADO, 2007, p. 49).

Para Ihering (1979), toda e qualquer cultura, história ou acontecimento tem um valor, que pode servir para melhorar as condições comportamentais do homem. Os movimentos que acontecem em defesa do ser humano, como o da pessoa com deficiência, que obteve significância, pois deste modo, foi adquirido melhorias para que estes sejam atendidos com qualidade na educação, assistência social, garantias jurídicas na cultura, dentre outros.

Nota-se que os movimentos em favor da pessoa com deficiência tiveram o intuito de garantir a sua inclusão em todos os aspectos, ações estas que tiveram grandes avanços com o passar do tempo. Alguns valores vêm sendo atribuídos e implantados na sociedade, incluindo os direitos fundamentais que asseguram às pessoas com deficiência no Brasil uma vida digna.

Recentemente, segundo Madruga (2016), o mais importante avanço foi sedimentado pela Lei $\mathrm{n}^{\circ}$ 13.146, de 06 de julho de 2015. Esta instituiu a Lei Brasileira de Inclusão (LBI) que também traz em seu art. $28^{\circ}$ o modelo social de como é o critério para analisar a deficiência ou até mesmo a pessoa com deficiência. A partir desses avanços, a legislação trouxe o respeito aos direitos humanos desses indivíduos.

O Estatuto da Pessoa com Deficiência sintetizou a concepção da política do estado Brasileiro dos últimos trinta anos. O movimento logrou êxito ao situar suas demandas no campo dos Direitos Humanos, às incluindo nos direitos de todos, sem distinção. (LANNA JÚNIOR , 2010).

Os avanços acerca dos direitos da pessoa com deficiência foram acontecendo de acordo com a necessidade de cada momento, os movimentos foram ganhando espaço na sociedade e conquistando seus objetivos cada vez que foram acontecendo. Os direitos fundamentais sem dúvida são considerados a maior conquista de garantia para proporcionar uma boa qualidade de vida para todos, em destaque aqui, pessoas com deficiência. 


\section{CAMINHOS DOS DIREITOS FUNDAMENTAIS}

Os caminhos dos Direitos Humanos e Fundamentais tiveram um longo percurso, foram anos de insistência e perseverança até que foram obtidas conquistas, assegurando garantias que fizeram e fazem muito sentido para o bem estar do ser humano.

A Declaração Universal de 1948 (ONU, 1948) nos leva a reconhecer a dignidade humana, alcançando todos os membros da família humana e garantindo seus direitos iguais e inalienáveis, é o verdadeiro fundamento da liberdade, da justiça e da paz. O desrespeito pelos direitos humanos resultou em atos bárbaros, que ultrapassaram a consciência da humanidade. O advento de um mundo em que mulheres e homens gozem da liberdade de palavra, crença e liberdade de viverem a salvo dos temores, foi proclamado neste documento como a mais alta aspiração do ser humano.

Ainda sobre a Declaração Universal 1948 (ONU, 1948), a mesma ressalta a importância dos direitos humanos serem protegidos por lei, para que esses não tenham seus direitos lesados, considera ser essencial promover o desenvolvimento de acordo com as realidades entre as nações. Destaca que os povos das Nações Unidas alicerçam suas propostas nos direitos essenciais do ser humano, na dignidade, no valor da pessoa humana e na igualdade de direitos do homem e da mulher.

Para Piovesan (2018), o Direito Internacional dos Direitos Humanos, pode trazer propósitos específicos e especiais, o que o diferencia do Direito Internacional Público em geral. Enquanto o mesmo procura abraçar relações recíprocas e equilíbrio entre Estados, através de negociações e concessões que buscam interessados próprios Estados pactuantes, o Direito Internacional dos Direitos Humanos tem o objetivo de garantir os direitos do ser humano.

Através do conceito de Mazzuoli (2018), os tratados internacionais de direitos humanos validados no Brasil, amparados em normas constitucionais, seja uma hierarquia somente material ou formal, não importa o número de aprovação do 
acordo formal, o resultado disso, é que esses acordos que estão em vigor no país são considerados também, como na Constituição, modelo de controle de normas, o que se denomina característica de leis que podem ser usadas tanto na ação das normas como na exceção. Portanto, para que a via de ação seja seguida devem os tratados de direitos humanos serem aprovados pela sistemática do art. 5. ${ }^{\circ}$ § 3.० , da Constituição, já o de exceção basta que sejam esses tratados executados e estejam em vigor no plano interno, pois, por força do art. 5.०, §.$^{\circ}$, da mesma Carta, já têm eles status de norma constitucional.

Diferente do que parece, ou do pensam alguns leigos, as garantias que os direitos fundamentais proporcionam são relativas, possuem limites e não são absolutos. Há algumas situações ou circunstâncias nas quais ela toma face de absoluta, em caso de tortura ou tratamento desumano contra alguém. (SAMPAIO, 2002).

Complementando toda a evolução, Assis e Kümpel (2011) entendem que a igualdade foi garantida pelo fato de serem percebidas as diferenças entre pessoas, se os seres humanos fossem iguais, o direito não teria tanto sentido nem tanta importância. A cidadania resulta do ter ou poder reivindicar os seus direitos, as ilegalidades ou injustiças acontecem pelo fato de muitos não saberem como garantir seus direitos.

Para Bulos (2015), são com todos esses desdobramentos que os direitos fundamentais trazem vida digna a uma pessoa com deficiência, seja amparos que a constituição garante, ou especificamente através de seu estatuto. A natureza dos direitos fundamentais originou-se de normas positivas e necessárias para o bem estar de todos, se pode afirmar que sem vida digna o homem não vive, não tem convivência e não sobrevive em algumas circunstâncias, são esses direitos fundamentais que trazem dignidade às pessoas. Os direitos fundamentais foram desenvolvidos por meio de períodos, esses foram responsáveis por demarcar a evolução de liberdades das pessoas.

Segundo Comparato (2004), o objetivo dos direitos fundamentais das pessoas com deficiência é corrigir as desigualdades sociais, econômicas e de qualidade de vida dos mesmos: 
[...] direitos fundamentais tem como terminologia pode ser rotulado em; direitos humanos fundamentais, direitos humanos, direitos do homem, direitos individuais, direitos públicos subjetivos, direitos naturais, liberdades fundamentais, liberdades públicas, entre outros.Com essas terminologias pode ser concluído que os direitos fundamentais são normas, princípios, prerrogativas, deveres e institutos inerentes à soberania popular, que garantem a boa convivência pacífica, digna livre e com igualdade, independente de credo, raça, origem, cor condição econômica ou status social. (BULOS, 2015, p. 292)

A Lei no 13.146/2015 instituiu a Lei de Inclusão da Pessoa com Deficiência, (Estatuto da Pessoa com Deficiência). Esta assegura e promove condições de igualdade, o exercício dos direitos e das liberdades fundamentais para esta parcela da sociedade, visando à sua inclusão social e cidadã. Esta lei respeita todos os limites que as pessoas com deficiência enfrentam na sociedade e até mesmo na economia. Abrange todas as limitações, barreiras e qualquer dificuldade que uma pessoa possa se deparar. (BRASIL, 2015)

Os direitos fundamentais, os quais são amparados na lei 13.146/2015, tiveram o cuidado de observar todos os aspectos, na tentativa de garantir melhor qualidade de vida e assegura a todos os seres humanos que seus direitos sejam invioláveis e efetivados com dignidade, garantindo ser reivindicados por qualquer pessoa que se sentir na necessidade de ter seus direitos exigidos quando precisar (BRASIL, 2015).

Diante da revisão da leitura sobre os desdobramentos dos direitos fundamentais, é possível identificar como é importante a aplicabilidade da lei em favor da pessoa com deficiência, assim como, a Constituição Federal que garantiu o Estatuto da Pessoa com Deficiência, ganharam mais força às conquistas necessárias para o bem estar desta população. A sociedade está cada vez mais consciente do seu papel de evocar a aplicabilidade das garantias, devendo cobrar eficiência e celeridade.

\section{A EFICÁCIA, OS CAMINHOS PARA EXECUÇÃO E OS PERIGOS DA NÃO EXECUÇÃO DA LEI}

Historicamente, as garantias para ampliação dos direitos das pessoas com deficiência vêm aumentando no Brasil, sobretudo, no aspecto formal. Em 2008, foi Revista Auditorium, Rio de Janeiro, v. 25, n. 52, p. 62-80, jul./out. 2021 
ratificado o status de emenda constitucional a Convenção sobre os Direitos das Pessoas com Deficiência, que foi uma iniciativa das Nações Unidas e seu protocolo facultativo, utilizando pela primeira vez $0 \S^{\circ}$ do artigo $5^{\circ}$ da Constituição Federal (BRASIL, 1988).

A partir dessa Convenção e a sua incorporação no ordenamento jurídico pátrio, foi Instituída a Lei Brasileira de Inclusão de Pessoas com Deficiência, que em seu primeiro artigo destaca o que esse documento busca: "assegurar e promover, o exercício dos direitos e das liberdades fundamentais das pessoas com deficiência, visando à sua inclusão social e cidadania." (BRASIL, 2015).

Os dispositivos da referida lei são voltados ao fomento e promoção da inclusão dos deficientes, contudo, é imperioso destacar que para uma mudança social não apenas a edição de leis é suficiente, pois como já dito, o aspecto apenas formal não garante efetivamente uma mudança na sociedade. A sociedade deve tê-la em seu alcance através de políticas públicas voltadas a essa população, pois desta maneira a lei terá a sua devida eficácia garantida, no sentido material. Desta forma, não será considerada "letra morta" e, com isso, as pessoas com deficiência poderão ter os seus direitos e garantias efetivadas e cumpridas devidamente (GARCIA, 2012).

Uma lei se tornar vigente e não ser aplicada na prática, de certo modo ela se torna insignificante. A modificação de paradigma da Lei 13.146/2015 (BRASIL, 2015), em relação à capacidade civil dos deficientes, foi um importante marco histórico na expectativa de aumentar o leque de possibilidades desses indivíduos, que passaram a atuar de maneira mais ativa nos vários âmbitos da vida civil conforme sua capacidade plena ou equivalente à capacidade de fato com as devidas restrições, ou seja, os que possuem capacidade relativa podem decidir algumas situações por si (CRUZ, 2009).

É contraproducente uma pessoa ter direitos declarados universalmente, e os mesmos não serem aplicados corretamente, esses precisam ser exercidos por toda a sociedade em que o indivíduo está inserido, isso implica que, a cidadania e suas características precisam ser respeitadas. Então, um ponto bastante considerável, além de ser uma das interrogações da Carta de 1988, é de como passar da esfera abstrata de princípios à materialidade das normas e exercício dos direitos estatuídos pela Carta Maior (FRISCHEISEN, 2000). 
É relevante destacar que os Poderes Públicos têm a função de garantir e efetivar em todo o território brasileiro, as normas internacionais com suas exigências referentes aos direitos humanos, as quais validadas pelo Brasil. As normas internacionais que fundam direitos e garantias fundamentais tornam-se capazes de introdução, aplicação ou execução perante o Poder Judiciário, ao passo que são precisamente aplicáveis. Portanto, as pessoas devem de forma direta, ser beneficiadas pelas patentes internacionais voltadas à proteção dos direitos humanos (PIOVESAN, 2018).

Nesse sentido, segundo o entendimento de Habermas (1997), em relação ao que se refere às pessoas com deficiência, não vem sendo assegurados os direitos humanos básicos como os direitos de ir e vir, de livre expressão, acesso ao trabalho, livre pensamento, entre outros. Esta ação global que convergiu na Organização das Nações Unidas desde os anos 80 e que perfez com o tratado ainda em análise, pode garantir uma efetiva ação libertária. Vale ressaltar, que em relação à colocação do tratado, concedeu-se o assunto na medida em que os institutos criados naquele momento foram resultantes das reivindicações milenares de pessoas com deficiências sensoriais, físicas, mentais e intelectuais e, conforme foi se confirmando. Facultam, por isso, ferramentas jurídicas conforme vão sendo confirmadas.

Para Rodrigues (2015), pode-se perceber que o contexto atual ainda não oferta condições apropriadas para que haja a inclusão das pessoas com deficiência de forma plena na sociedade. Esse assunto foi referido pelo IBGE, que o expôs no Censo 2010. Na pesquisa foram identificados os tipos de deficiências, que podem se caracterizar como: mentais, físicas e auditivas, uma parcela da população que anseia por melhores condições.

A maior parte dos deficientes ainda encontra empecilho para a inserção no mercado de trabalho, os dados levantados pelo IBGE no Censo 2010, revelam que, a discussão sobre as barreiras enfrentadas para a inclusão das pessoas com deficiência decorre da responsabilidade do Estado, seja por conduta de ação ou omissão. $\mathrm{Na}$ seara da sociedade civil, nota-se que muitas vezes a mesma não se organiza para o cumprimento da legislação vigente, o que ultrapassa as barreiras arquitetônicas.

Apesar da lentidão observada, pode-se notar um alavancar em relação às medidas protetivas. A política de cotas trazida da esfera trabalhista pela Lei $n^{\circ} 8.213$, Revista Auditorium, Rio de Janeiro, v. 25, n. 52, p. 62-80, jul./out. 2021 
de 24 de julho de 1991 (BRASIL, 1991), que permite empregadores contratarem pessoas com deficiência por meio de um percentual definido sobre o número de funcionários de uma determinada empresa. Essa forma de permissão para o trabalho foi vista como um divisor de águas e um grande destaque sobre esse tema, porém, chamou atenção para o que se refere à existência de hoje em termos de legislação e políticas públicas é suficiente.

\section{CONSIDERAÇÕES FINAIS}

Pôde-se perceber, por meio da linha do tempo traçada no decorrer do referencial teórico que os direitos humanos e os direitos da pessoa com deficiência, independentemente de seu caráter, sejam eles em qualquer âmbito da sociedade, são frutos colhidos de uma longa e batalhadora evolução histórica.

Por meio dos períodos cronologicamente evidenciados no decorrer do texto, pôde-se perceber que, mesmo com a identificação dos progressos e avanços conquistados, esses se deram a passos lentos, demandando muitos estudos, bem como foi evidenciada a necessidade de participação da sociedade, das autoridades e auto defensores envolvidos na temática proposta nesta pesquisa, que também se importaram com as civilizações humanas, e dessa forma estes foram comparecendo aos poucos e até chegarem aos objetivos buscados.

Nesse viés, está claro que os direitos humanos não são o que parece ser uma mera autolimitação do Estado, e sim frutos de longas lutas e revoluções, e de caminhar insistente e incansável do desenvolvimento histórico, que culminaram em avanços à humanidade.

Por conseguinte, pode-se afirmar que todos os direitos mencionados são essenciais para melhor qualidade de vida para humanidade, e nessa afirmação, não se pode esquecer de incluir como beneficiários as pessoas com deficiência elencadas, nos seus mais variados tipos, de acordo com a Lei no 13.146 (BRASIL, 2015).

Somente dessa forma, e com ações afirmativas a exemplo das evidenciadas no decorrer do tempo é que se pode identificar as melhorias conforme a sociedade evolui, sem deixar de levar em consideração as possíveis conquistas relacionadas às novas tecnologias, novos estudos e novos conhecimentos. Também surgem destas Revista Auditorium, Rio de Janeiro, v. 25, n. 52, p. 62-80, jul./out. 2021 
evoluções, novos direitos considerados primordiais para a garantia da pessoa humana.

O livre desenvolvimento da personalidade e deveres atribuídos à pessoa com deficiência em uma dada sociedade, são exemplos de evoluções e avanços que vão nascendo conforme o caminhar da civilização.

Compreender todas essas normativas relativas aos direitos humanos e à inclusão, impulsiona a uma reflexão crítica com bases principiológicas que contribuem para o alcance da finalidade geral, que é a efetivação dos direitos da pessoa com deficiência.

É possível perceber que, mediante a produção científica do conhecimento, se alcança a base para a sociedade como todo edificar documentos e políticas de Acessibilidade nas mais variadas abordagens, a exemplo de: Inclusão e Permanência; Infraestrutura Acessível; Acessibilidade Pedagógica e Curricular nos níveis educacionais; Acessibilidade Comunicacional e Informacional; Catalogação das Informações sobre Acessibilidade.

Torna-se viável ainda afirmar que é necessário dar subsídios para a iniciativa pública e privada assegurar não só os direitos humanos como também uma sociedade pautado na acessibilidade da pessoa com deficiência, sob todos os aspectos preconizados na Lei no 13.146 (BRASIL, 2015), e o passo importante pode ser dado através da difusão do conhecimento, bem como de qualquer experiência exitosa alcançada onde a pessoa com deficiência é a beneficiada. 


\section{REFERÊNCIAS}

ARAUJO, Luiz Alberto; JÚNIOR, Vidal Serrano Nunes. Curso de Direito

Constitucional. 10. ed. rev. atual. São Paulo: Saraiva, 2006.

ASSIS, Olney Queiroz; KÜMPEL, Vitor Frederico. Manual de antropologia jurídica. 2. ed. São Paulo: Saraiva, 2011.

BRASIL. [Constituição (1988)]. Constituição da República Federativa do Brasil de 1988. Brasília, DF: Presidência da República, [2020]. Disponível em: http://www.planalto.gov.br/ccivil_03/constituicao/constituicao.htm. Acesso em: 30 maio 2021.

BRASIL. Lei no 13.140, de 26 de junho de 2015. Estatuto da pessoa com deficiência. Brasília, DF: Presidência da República, 26 jun. 2015. Disponível em: http://www.planalto.gov.br/ccivil_03/_ato2015-2018/2015/lei/l13140.htm. Acesso em: 15 maio 2021.

BULOS, Uadi Lâmmego. Direito constitucional ao alcance de todos. 6. ed. São Paulo: Saraiva, 2015.

COMPARATO, Fábio Konder. A afirmação histórica dos direitos humanos. 3. ed. rev. ampl. São Paulo: Saraiva, 2004.

CRUZ, Álvaro Ricardo de Souza. O Direito à Diferença. 3. ed. Belo Horizonte: Arraes Editora, 2009.

CUNHA, Eugênio. Autismo e Inclusão: Psicopedagogia prática educativas na escola e família. 5. ed. Rio de Janeiro: Wak Editora, 2014.

DALLARI, Dalmo de Abreu. A Constituição na vida dos povos: da Idade Média ao Século XXI. 2. ed. São Paulo: Saraiva, 2013.

DELGADO, Mauricio Godinho. Curso de direito do trabalho. 6. ed. São Paulo: LTR, 2007.

FACION, José Raimundo. Transtornos invasivos do desenvolvimento e transtornos de comportamento disruptivo. 2. ed. atual. Curitiba: IBPEX, 2005.

FRISCHEISEN, Luiza Cristina Fonseca. Políticas públicas: a responsabilidade do administrador e o Ministério Público. São Paulo: Max Limonad, 2000.

GARCIA, Rebeca Alves de Souza. A Inclusão da Pessoa com Deficiência no Mercado de Trabalho: medidas de discriminação positiva, seus mitos e suas possibilidades. 2012. Dissertação (Mestrado em Direito), Universidade Presbiteriana 
Mackenzie, São Paulo, 2012. Disponível em:

http://tede.mackenzie.br/jspui/handle/tede/1061. Acesso em: 24 maio 2021

HABERMAS, Jurgen. Direito e Democracia: entre facticidade e validade. Rio de Janeiro: Tempo Brasileiro, 1997. vol. I.

IHERING, Rudolfo Von. A finalidade do direito. 3. ed. Rio de Janeiro: Editora Rio, 1979.

LAKATOS, Eva Maria; MARCONI, Marina de Andrade. Metodologia Científica. 7. ed. São Paulo: Atlas, 2017.

LANNA JÚNIOR, Mário Cléber Martins (comp.). História do Movimento Político das Pessoas com Deficiência no Brasil. Brasília: Secretaria de Direitos Humanos; Secretaria Nacional de Promoção dos Direitos da Pessoa com Deficiência, 2010.

MADRUGA, Sidney. Pessoas com Deficiência e Direitos Humanos: ótica da diferença e ações afirmativas. 2. ed. São Paulo: Saraiva, 2016.

MADRUGA, Sidney. Pessoas com Deficiência e Direitos Humanos. 3. ed. São Paulo: Saraiva, 2019.

MAZZUOLI, Valério de Oliveira. Controle Jurisdicional da convencionalidade das leis. 5. ed. rev. ampl. atual. Rio de Janeiro: Forense, 2018.

MEZZAROBA, Orides; MONTEIRO, Claudia Servilha. Manual de Metodologia da Pesquisa no Direito. 8. ed. São Paulo: Saraiva, 2019.

NABAIS, José Casalta. A Face oculta dos Direitos Fundamentais: Os Deveres e custos dos Direitos. Revista Direito Mackenzie, São Paulo, v. 3, n. 2, p. 9-30, 2002. Disponível em:

http://editorarevistas.mackenzie.br/index.php/rmd/article/view/7246/4913. Acesso em: 05 maio 2021.

OEA. Convenção Americana de Direitos Humanos. San José da Costa Rica: OEA, 1969. Disponível em:

http://www.pge.sp.gov.br/centrodeestudos/bibliotecavirtual/instrumentos/sanjose.ht m. Acesso em: 30 de maio de 2021.

ONU. Declaração Universal dos Direitos Humanos. Nova York: ONU, 1948. Disponível em:

https://www.oas.org/dil/port/1948\%20Declara\%C3\%A7\%C3\%A30\%20Universal\%20 dos\%20Direitos\%20Humanos.pdf. Acesso em: 28 mai. 2021.

PIOVESAN, Flávia. Direitos humanos e o direito constitucional internacional. 18. ed. rev. atual. São Paulo: Saraiva, 2018. 
RODRIGUES, Luiz Carlos. A inclusão de pessoas portadoras de deficiências nas organizações como oportunidade para o desenvolvimento local. In: II Congresso Brasileiro de processo coletivo e cidadania da universidade de Ribeirão Preto, 3. 2015, Ribeirão Preto. Anais do congresso brasileiro de processo coletivo e cidadania. Ribeirão Preto: Universidade de Ribeirão Preto, 2015. Disponível em: https://revistas.unaerp.br/cbpcc/article/view/503/607. Acesso em: 07 jun. 2021.

ROTHENBURG, Walter Claudius. Princípios constitucionais. 2. ed. Porto Alegre: Sergio Antonio Fabris, 2003.

SAMPAIO, José Adércio Leite. A Constituição reinventada pela jurisdição constitucional. Belo Horizonte: Del Rey, 2002. 